\title{
Energy conversion in small water plants with variable speed $P M$ generator
}

\author{
Institute of Electromechanical Energy Conversion \\ Cracow University of Technology \\ Warszawska 24, 31-155 Kraków, Poland \\ e-mail: pesobczy@cyfronet.pl
}

Tadeusz J. SobczyK, Witold MazgaJ, Zbigniew Szular, Tomasz WęGiel

(Received: 02.07.2010, revised: 08.12.2010)

\begin{abstract}
The Small Hydro Power Plants allow to increase the energy amount from renewable sources, especially from small rivers in mountainous areas. This paper presents a new concept of a energy conversion system for application in a Small Hydropower Plant (SHP) which is based on a permanent magnet generator (PM generator) with a propeller turbine integrated with the generator rotor. The PM generator can work at a variable speed and therefore energy produced by the PM generator has to be converted by means of a power electronic unit to fit to the three-phase power grid parameters. For this concept, dimensions and parameters of the PM generator were specially designed on account of integration with water turbine. The paper precisely describes elements of energy conversion system and also presents the results of numerical tests for chosen working conditions. An original algorithm of control strategy for power electronic unit was used to adjust generated energy to the required parameters of the three-phase grid.
\end{abstract}

Key words: permanent magnet generator, PWM rectifier, small hydro power

\section{Introduction}

Small Hydro Power Plants (SHP) are widely used across the world. Electrical generators for today's small hydro power-plants are designed for a constant rotation speed, which is kept by a speed controller often consisting of mechanical equipment. Changes of energy provided by water depend on water flow which is very unreliable for small rivers in mountainous areas. Therefore, full efficiency can be achieved for power technology with generators working at variable speed. So, in this paper a new solution of a PM generator integrated with a propeller turbine working with variable speed will be discussed [1]. It is assumed that the mechanical system for speed control via the change of the angle of turbine blades will be removed. This leads to an essential simplification of mechanical systems but this in turn requires an application of a power electronic unit (PEU) in electrical system. The rotation speed of propeller turbine will be variable and for a certain water flow should be controlled by the PEU to ensure 
the highest possible efficiency [2]. Due to the non-linear turbine characteristics it is necessary to formulate a suitable control algorithm for the whole system of energy conversion. Therefore, the PEU have to be applied not only to ensure the output frequency and voltages required by the power grid, but also to control the energy flow from generator to the three-phase grid.

This solution of the energy conversion system with PM generator and PEU will be applied in Experimental Power Station of Cracow University of Technology. Partial results of investigations are presented in further part of this article.

\section{Turbine integrated with PM generator}

The hydro-set is based on a tubular turbine construction where the working fluid changes pressure while it moves through the turbine, giving up its energy. Typical solutions utilize shaft to transfer torque from a turbine impeller to a certain generator (synchronous or induction). This new construction avoids the need of a shaft and a shaft guide system. The torque is transferred by a special external ring being an integrated part of the turbine impeller. This system is simple and durable and, therefore it is assumed that it does not require no special service. Figure 1 shows a view of a complete hydro-set.

Permanent magnets are mounted on the external surface of the external ring [3] and the spaces between magnets are filled with non-magnetic epoxy resin. Both internal surface of the stator and external surface of the rotor are protected by waterproof tubes. Water flows between the rotor and the stator ensures generator's self-cooling system, so that the stator windings and permanent magnets are subjected to good cooling conditions.

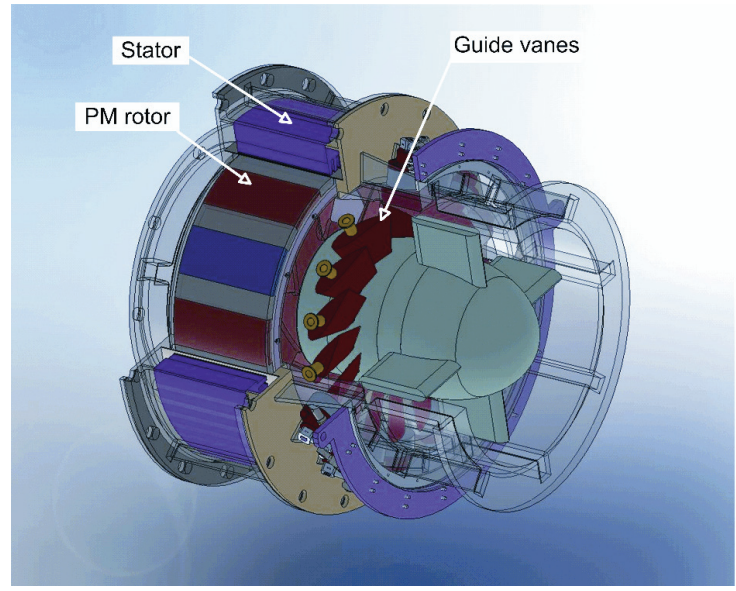

Fig. 1. View of a hydro-set

Guide vanes direct the water to the turbine vanes (Fig. 1). The water flow acts on the runner's blades (Fig. 2), causing the runner to rotate. The guide vanes can be adjusted to allow 
efficient turbine operation for a wide range of water flow conditions and continuous production of power with the highest possible efficiency.

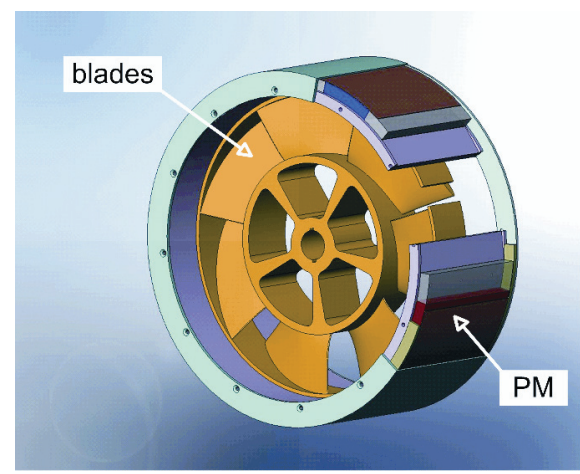

Fig. 2. Location of permanent magnets on the rotor

The maximum values of power produced by the turbine, as well as the turbine efficiency for changes of guide vanes position are achieved for different values of rotor speed. Therefore, the characteristics which describe relations between the power of turbine $P_{m}$ and its rotation speed $\omega$ (Fig. 3) should be stored in the control system memory. The turbine characteristics, presented in Fig. 3, are determined on the basis on experimental turbine model tests [4].

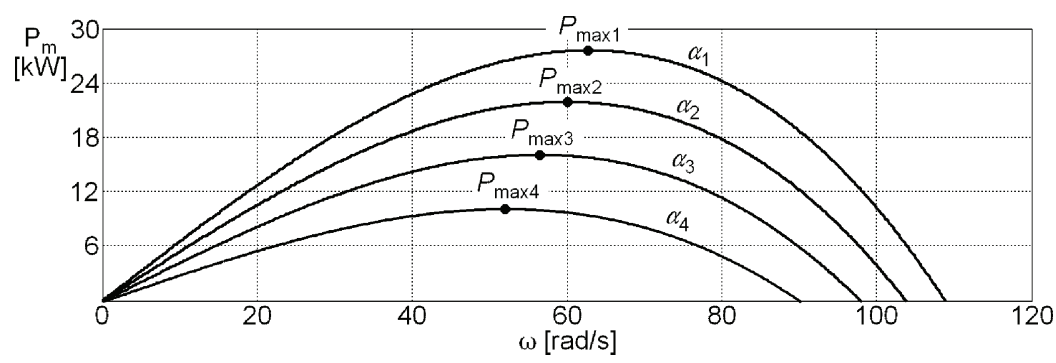

Fig. 3. Power-rotation speed characteristics $P_{m}=f(\omega, \alpha) ; \alpha_{1}=\alpha_{\max }=90^{0}, \alpha_{1}>\alpha_{2}>\alpha_{3}>\alpha_{4}$

Changes of the guide vanes angle $\alpha$ can be caused by signals of low water level or a lack of grid energy consumption what requires the reduction of the energy production. This angle is equal to 90 degrees if the guide vanes are full open. This angle is close to zero when the hydro-set inlet is closed. In consequence the regulation system of guide vanes should be an integral part of whole system of energy conversion. The non-linear characteristics of turbine should be implemented in the control algorithm.

The PM generator should be specially designed for the sake of turbine dimensions. Its design should ensure a water protection, a proper parameters of a generator, especially its internal reactance $X_{d}$ and electromotive force EMF. A designed 3-phase PM generator for application in experimental power station have the nominal data: $P_{N}=30 \mathrm{~kW}, U_{N}=500 \mathrm{~V}$, $I_{N}=34.7 \mathrm{~A}, f=50 \mathrm{~Hz}, n_{N}=600 \mathrm{rpm}, p=5$. The designed $\mathrm{PM}$ generator has the following dimensions: outer stator core diameter $-850 \mathrm{~mm}$, inner stator core diameter $-670 \mathrm{~mm}$, air gap - 
$6 \mathrm{~mm}$, and axial length $-90 \mathrm{~mm}$. The residual flux density of the permanent magnets is equal to $1,2 \mathrm{~T}$, and coercive force $891 \mathrm{kA} / \mathrm{m}$.

The mathematical model of this hydro-set (generator integrated with turbine) which assuming the base-harmonic of MMF and magnetic linearity is following:

$$
\begin{gathered}
\left(\left[\begin{array}{ccc}
L_{\sigma s} & M_{\sigma s} & M_{\sigma s} \\
M_{\sigma s} & L_{\sigma s} & M_{\sigma s} \\
M_{\sigma s} & M_{\sigma s} & L_{\sigma s}
\end{array}\right]+\left[\begin{array}{ccc}
L_{s} & M_{s} & M_{s} \\
M_{s} & L_{s} & M_{s} \\
M_{s} & M_{s} & L_{s}
\end{array}\right]\right) \frac{d}{d t}\left[\begin{array}{c}
i_{1} \\
i_{2} \\
i_{3}
\end{array}\right]= \\
=\left[\begin{array}{l}
u_{1} \\
u_{2} \\
u_{3}
\end{array}\right]+p \omega \psi_{m}\left[\begin{array}{c}
\sin (p \omega t) \\
\sin \left(p \omega t-\frac{2 \pi}{3}\right) \\
\sin \left(p \omega t-\frac{4 \pi}{3}\right)
\end{array}\right]-R_{s}\left[\begin{array}{c}
i_{1} \\
i_{2} \\
i_{3}
\end{array}\right], \\
J \frac{d \omega}{d t}=\omega \psi_{m}\left\{i_{1} \sin (p \omega t)+i_{2} \sin \left(p \omega t-\frac{2 \pi}{3}\right)+i_{3} \sin \left(p \omega t-\frac{4 \pi}{3}\right)\right\}+T_{l}-D \omega,
\end{gathered}
$$

where $\omega$ is turbine rotor speed, $J$ denotes moment of inertia of turbine rotor, $D$ is friction in mechanical system, and $T_{l}$ presents torque produced by turbine $\left(T_{l}=P_{m} / \omega\right.$, where $P_{m}$ is according to Fig. 3).

The length of the PM generator air gap and the thickness of the permanent magnets are relatively large. It allowed us to assume that the main magnetic circuit of this generator is linear. This assumption was also confirmed by field computations, which were made for currentless and nominal current states. Figure 4 presents, for example, the magnetic field distribution (obtained on the basis of the FEM analysis in MagNet software) in a part of generator cross-section.

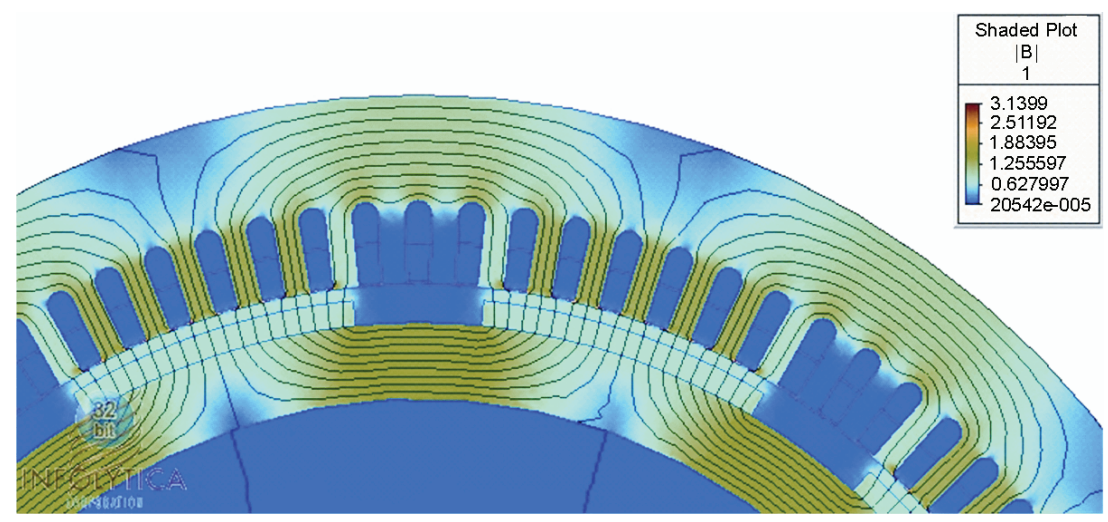

Fig. 4. Magnetic field distribution in a part of generator cross-section

The field calculations allowed us to approximate winding self inductances, mutual inductances and PM flux leakage with the windings. The calculation of main inductances executed 
for machine model without magnets but leakage inductances required computation for the machine model without rotor (according to Fig. 5a and b).
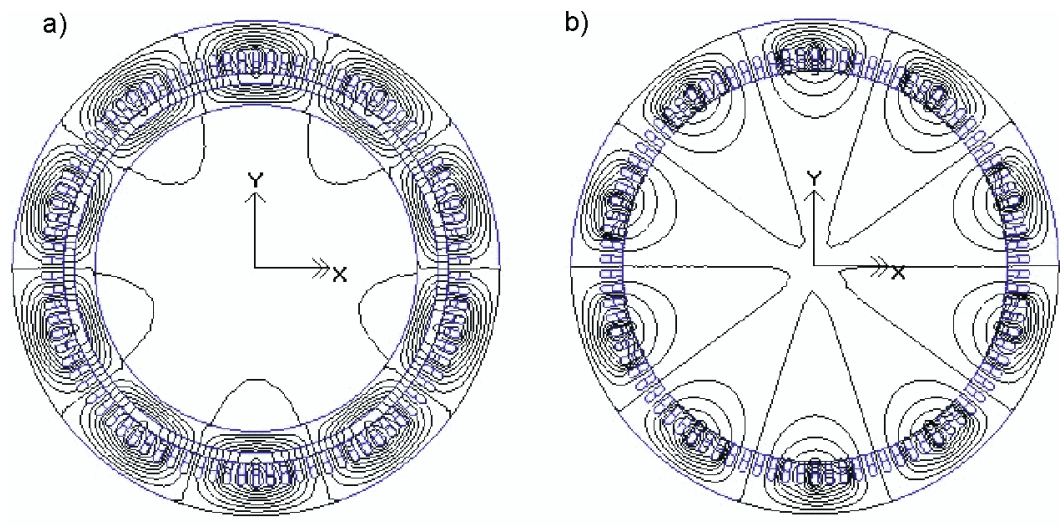

Fig. 5. Distribution of magnetic field force lines: a) machine without magnets, b) machine without rotor

The results of parameter computations for mathematical model of PM generator are as follows: $L_{s}=1.41 \mathrm{mH}, \quad M_{s} \approx-0,5, \quad L_{s}=-0.69 \mathrm{mH}, \quad L_{\sigma s}=0.99 \mathrm{mH}, \quad L_{\sigma s}=-0.32 \mathrm{mH}, \quad\left(L_{d}=3.42 \mathrm{mH}\right.$, $\left.X_{d}=1.07 \Omega\right), \psi_{m}=1.36 \mathrm{~Wb}$.

\section{Power electronic unit}

The RMS voltage and the frequency of the PM generator can change about $\pm 30 \%$ with respect to nominal values since the hydro-set operates with variable speed. In the proposed energy conversion system energy produced by the generator is converted into direct current energy (DC link), and then it is transferred to power grid $(3 \times 400 \mathrm{~V}, 50 \mathrm{~Hz})$ via voltage source inverter [5]. In practice, two schemes of energy conversion are used, especially with reference to wind turbine. The first one is based on an uncontrolled rectifier and DC/DC converter which can increase or decrease DC voltage. In the other one a PWM rectifier is applied. In both cases, the voltage source inverter is coupled with power grid using transformer or induction chokes.

The first method of energy conversion is not recommended because the uncontrolled rectifier can cause significant distortion of the generator currents with respect to sinusoidal shapes. As a result of this distortion the generator torque contains an alternating component with relatively high amplitude [6]. It is a certain disadvantage since the presence of this alternating component of the torque can significantly influence durability and reliability of the turbine generator unit. An application of the PWM rectifier results in almost sinusoidal shapes of the generator currents. The energy conversion system (Fig. 6), presented in this paper, does not differ fundamentally from solutions which are applied in wind power plants, however, the control system of this energy conversion unit is different than the one for windmill. 
The amount of energy produced by the PM generator is determined to a large degree by the guide vanes angle. The value of this angle depends on current hydrological conditions (water level in a water reservoir).

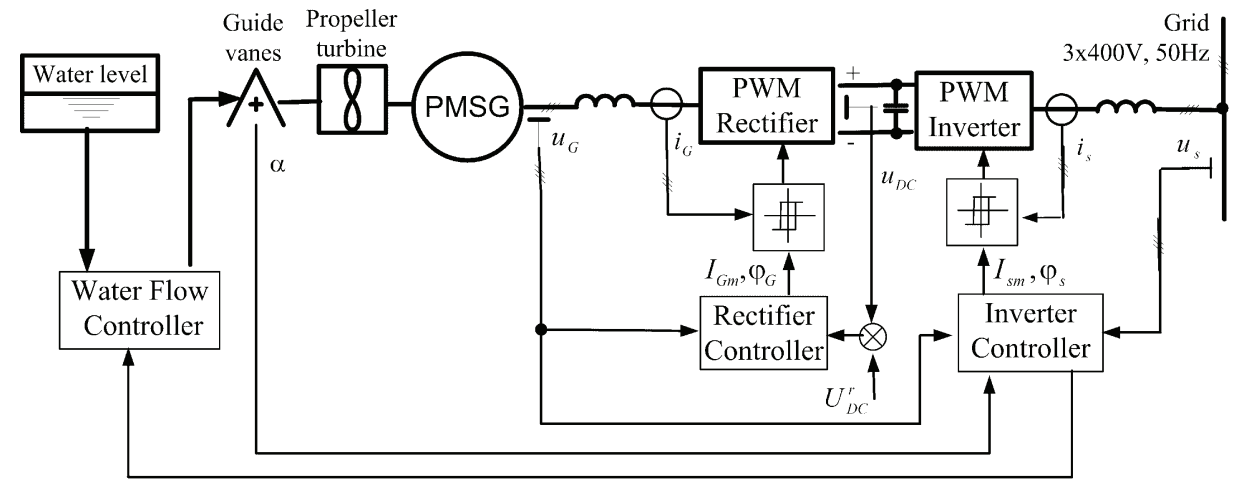

Fig. 6. Control units of energy conversion system

\section{Control strategy}

The fundamental purpose of the proposed control strategy is to transfer maximum possible amount of energy produced by the hydro-set, to the power grid. The amount of energy, which is transferred to the power grid, will be lowered if the hydrological conditions become worse. It means that the water stream flowing through the turbine reduces. The second task of the control unit is to decrease the THD factor in the current flowing to the three-phase grid.

The energy which can be transferred to the three-phase grid is calculated for the current angle $\alpha$ of the guide vanes. For the given angle $\alpha$, the PM generator produces the maximum energy amount if it rotates at the speed determined on the basis of the characteristic $P_{m}=f(\omega)$. This speed is being compared with the real speed value which is calculated on the basis of the generator voltage frequency. The proportional plus integral controller $R \omega$ (Fig. 7) of the generator speed determines the amplitude $I_{s m}$ of the current $i_{s}(t)$ flowing to the three-phase grid.

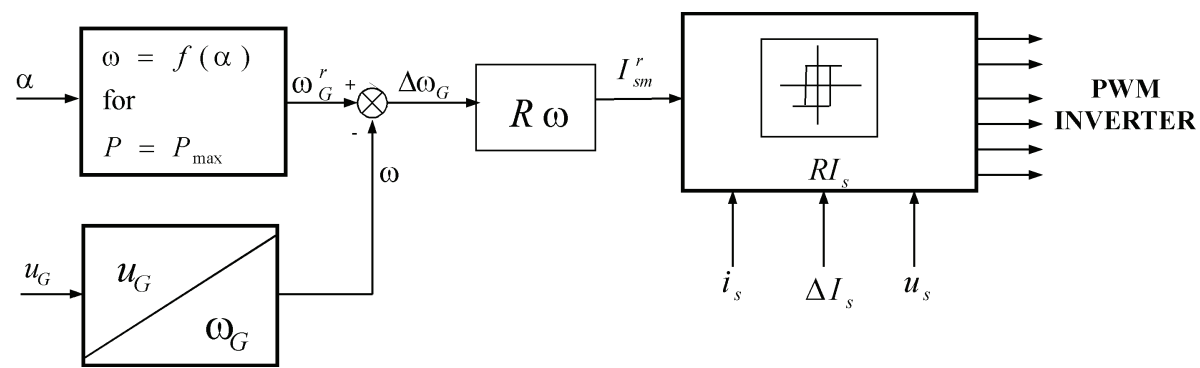

Fig. 7. Simplified form of the PWM inverter control system 
The generator voltage $u_{G}(t)$ is necessary to calculate the generator speed value (on the basis on the generator voltage frequency). The transistors of the voltage source inverter are controlled according to the given sinusoidal current signals using hysteresis controllers, separately for each phase of the voltage source inverter.

The application of the hysteresis controllers is the reason that the current flowing to the three-phase grid changes between exactly determined sinusoidal curves in respect to the given sinusoidal waveform $i^{r}(t)$ (Fig. 8). As a result of this, the THD factor can reach a satisfactorily low level. It is well known, that the voltage source inverter with the hysteresis controller operates at a variable frequency. This frequency depends on the assumed value $\Delta I_{s}$, and on the choke inductance, which connects the voltage source inverter with the three-phase grid.

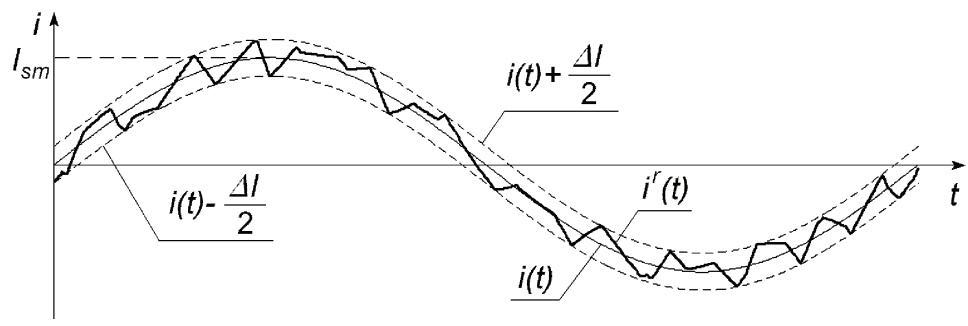

Fig. 8. Principle of the hysteresis controller operation

It is assumed that the phase shift between the given current signals and appropriate phase voltages of the three-phase grid is almost equal to zero (unity power factor). The transistors of the PWM rectifier are controlled similarly as in the PWM inverter. The amplitude $I_{G m}$ of the given current signals should have a value which permits to keep voltage in $D C$ link on the assumed level (about $800 \mathrm{~V}$ ). The proportional plus integral controller $R U_{D C}$ (Fig. 9) of the voltage in the $D C$ link determines the amplitude $I_{G m}$ of the generator current $i_{G}(t)$.

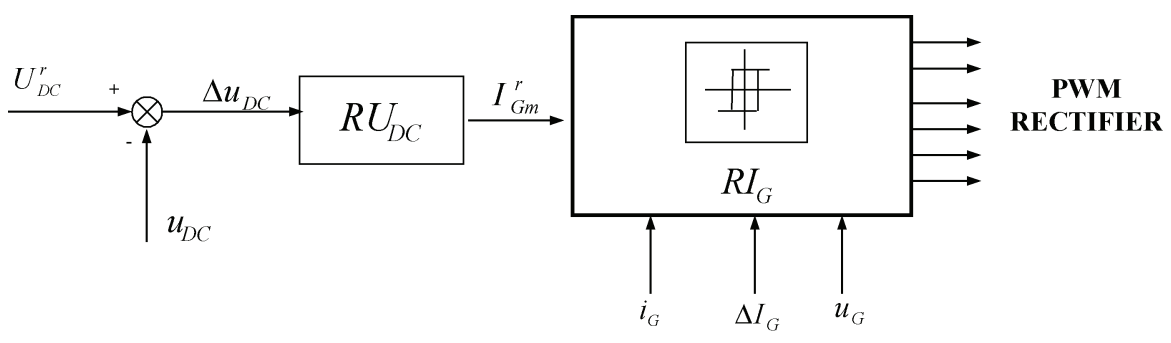

Fig. 9. The PWM rectifier control system

In this case, the output generator voltage $u_{G}(t)$ is necessary to calculate the frequency of the generator current signal. These current signals are synchronized with the output voltages of the PM generator. In general, phase shifts between voltages and currents of both converters are equal to zero, although, these shifts can be changed.

The analysis was made for the energy conversion system with nominal parameters which were mentioned previously. Numerical calculations were made with the use of the IsSPICE 
program. The IGBT's elements are substituted by variable resistances; $0,01 \Omega$ if IGBT is turned on or $1 \mathrm{M} \Omega$ if IGBT is turned off. The equations of the proportional plus integral controller are taken into account by means of the suitable electric circuits. In the analyzed case the choke inductance was equal to $5 \mathrm{mH}$, and the $\mathrm{DC}$ capacitor had $1 \mathrm{mF}$. Numerical calculations were performed for chosen working cases which differ due to changeable hydrological conditions. The waveforms of chosen currents and voltages for certain working conditions (which differ from nominal conditions) of the energy conversion system are shown in Fig. 10. It was assumed that the guide vanes angle $\alpha$ is less than $\alpha_{\max }$. In this case the power output of the generator is about $24 \mathrm{~kW}$. According to the characteristic $P_{m}=f(\omega)$, at the optimal working point, the generator rotates with $440 \mathrm{rpm}$ and its voltages and currents have frequency about $37 \mathrm{~Hz}$. Due to the application of the hysteresis controllers the generator and the PWM inverter currents contain certain higher harmonics, but the THD factor of these currents are less than six per cent. It is worth to underline that frequencies of transistor switching in the PWM rectifier and converter are not constant and they depend on the assumed hysteresis width. In the presented case these frequencies change between $2 \mathrm{kHz}$ and $3 \mathrm{kHz}$.
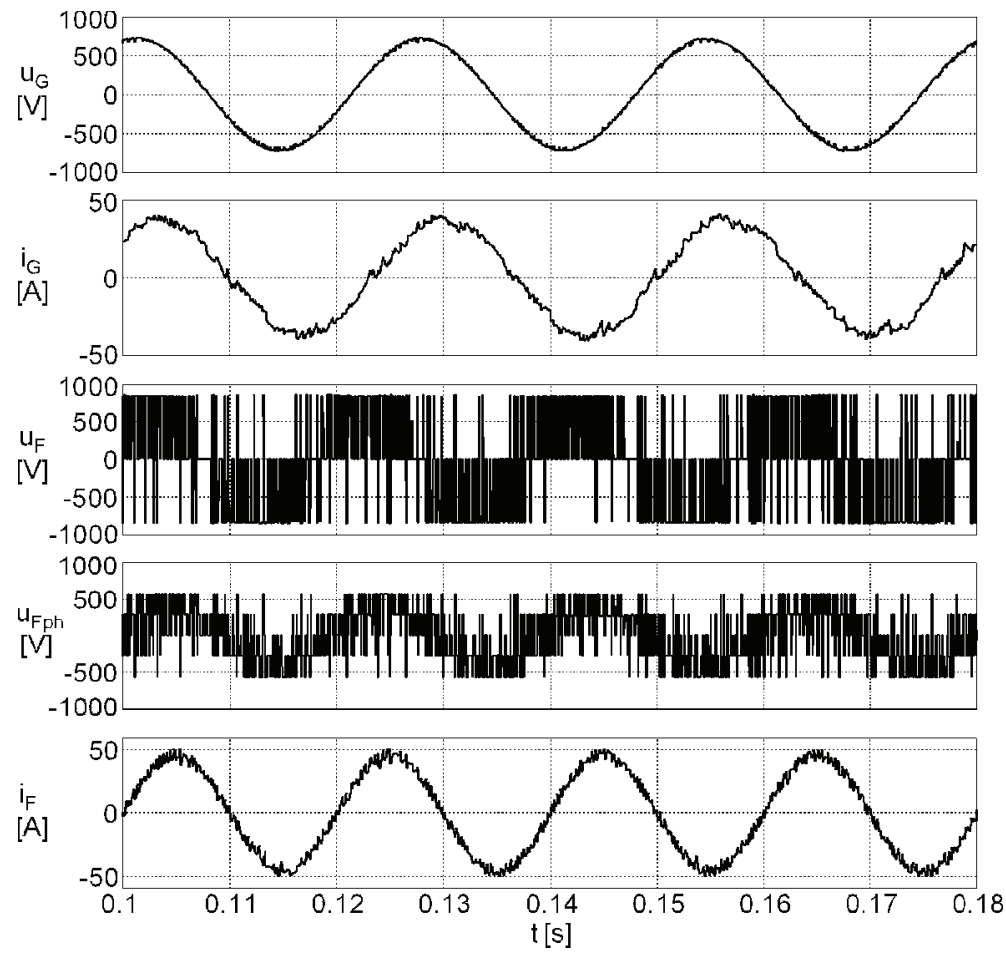

Fig. 10. Waveforms in power electronic unit: $u_{G}, i_{G}$ - phase-to-phase voltage and current of the PM generator, $u_{F}, u_{F p h}, i_{F}$ - phase-to-phase voltage, phase voltage and current of the PWM inverter respectively

The control unit should ensure correct operation of the whole energy conversion system during changes of working conditions. One of typical working conditions is any change of the 
guide vanes angle $\alpha$, which can be an after-effect of changes in hydrological conditions. It is necessary to stress that the guide vanes angle $\alpha$ changes much slower with respect to electric quantities. So, this angle can be treated as a constant value in the control system. Figure 11 presents chosen waveforms when the angle $\alpha$ is being changed from 90 to about 45 degrees. In order to show this energy conversion system working it was assumed that the hydro-set moment of inertia is 15 times lesser than the real value. The PWM inverter controller decreases the current amplitude, which flows to the three-phase grid. The voltage in the DC link raises to $850 \mathrm{~V}$, since the change of the generator current amplitude follows with a certain delay. This increase of DC link voltage causes the reaction of the rectifier controller witch decreases this amplitude. As a result of this, the amount of energy produced by generator become lower than previously. The energy amount, which can be transferred to the three-phase grid, increases if the guide vanes are full open again. Then, the inverter controller sets higher amplitude of the PWM inverter current. Next the voltage in the DC link decreases, therefore the rectifier controller causes an increasing of the PWM rectifier current amplitude.
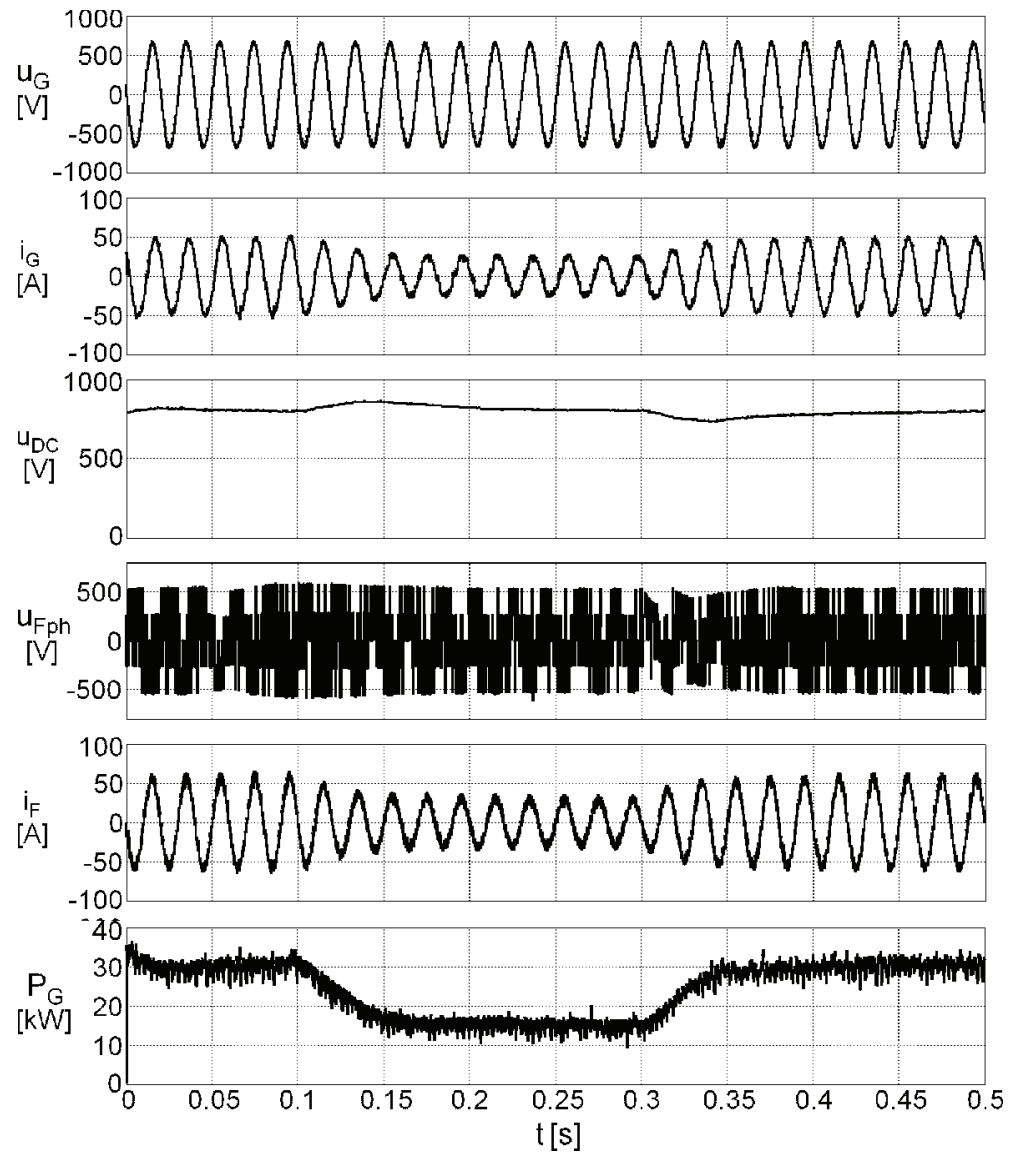

Fig. 11. Waveforms during the change of the guide vanes angle $\alpha: u_{D C}$-voltage in DC link, $P_{G}-$ generator power 


\section{Conclusions}

The described hydro-set has some advantages in comparison to classical hydro-generators with Kaplan turbines. The mechanical part of that hydro-set is essentially simplified: a shaft does not exist, a transmission gear is not necessary and a blades position control system is eliminated. All these facts have significant influence on investment costs and reliability of the whole Small Hydro Power plant.

Unlike energy conversion systems in windmill plants the control algorithm presented in this paper is relatively simply. The generator and PWM inverter currents are directly shaped by means of hysteresis controllers. Thank to this, the THD factor of these currents is satisfactorily low. The proposed control algorithm ensures correct operation of the whole energy conversion system in different working conditions.

\section{References}

[1] Binder A., Schneider T., Permanent magnet synchronous generators for regenerative energy conversion a survey. Proc. of $11^{\text {th }}$ European Conf. on Power Electronics and Applications, Dresden (2005).

[2] Koczara W., Chlodnicki Z., Ernest E. at al., Theory of the adjustable speed generation systems. COMPEL: The International Journal for Computation and Mathematics in Electrical and Electronic Engineering 27(5): 1162-1177 (2008).

[3] El-Refaie A.M., Jahns T.M., Comparison of synchronous PM machine types for wide constant-power speed range operations. COMPEL: The International Journal for Computation and Mathematics in Electrical and Electronic Engineering 27(5): 967-984 (2008).

[4] Ardanuy J.F., Wilhelmi J.R., Mora J.J.F., Perez J.I., Variable-speed hydro generation: operational aspects and control. IEEE Transactions on Energy Conversion 21(2): 569-574 (2006).

[5] Baroudi J., Dinavahi V., Knight A., A review of power converters topologies for wind generators. Renewable Energy 32: 2369-2385 (2007).

[6] Danilevicz Y., Drozdowski P., Mazgaj W. et al., The influence of failures of a multiphase p.m. synchronous generator and a static voltage converter system on the generator electromagnetic torque. Proc. of PowerTech 2005 Conf. Sankt Petersburg, paper number 520 (2005). 